\title{
Prevalence and the Association of Body Mass Index and Other Risk Factors with Prediabetes and Type 2 Diabetes Among 50,867 Adults in China and Sweden: A Cross-Sectional Study
}

\author{
Yue Zhang - Ailiana Santosa - Na Wang - Weibing Wang • \\ Nawi Ng • Qi Zhao · Yonggen Jiang · Lars Weinehall • \\ Genming Zhao
}

Received: July 30, 2019 / Published online: September 11, 2019

(C) The Author(s) 2019

\begin{abstract}
Introduction: Understanding socioeconomic differences for prediabetes and type 2 diabetes (T2DM) can offer guidance for the most effective development of both prevention and intervention programmes in different settings. This study aims to determine the prevalence and risk factors for prediabetes and T2DM and to explore the effect of high body mass index (BMI) on the probability of T2DM being present among adults in China and Sweden.
\end{abstract}

Yue Zhang and Ailiana Santosa should be considered as joint first authors.

Enhanced Digital Features To view enhanced digital features for this article go to https://doi.org/10.6084/ m9.figshare.9735869.

Electronic Supplementary Material The online version of this article (https://doi.org/10.1007/s13300019-00690-3) contains supplementary material, which is available to authorized users.

Y. Zhang · N. Wang · W. Wang . Q. Zhao .

G. Zhao ( $\square)$

School of Public Health, Key Laboratory of Public

Health Safety of Ministry of Education, Fudan

University, Shanghai, China

e-mail: gmzhao@shmu.edu.cn

A. Santosa $\cdot \mathrm{N} . \mathrm{Ng} \cdot \mathrm{L}$. Weinehall $(\bowtie)$

Department of Epidemiology and Global Health,

Faculty of Medicine, Umeå University, Umeå,

Sweden

e-mail: lars.weinehall@umu.se
Methods: This study enrolled 25,356 adults (35-64 years old) from the Shanghai Survey in China and 25,511 adults (aged 40, 50, 60) from the Västerbotten Intervention Programme in Sweden. Data on haemoglobin A1c, capillary fasting plasma glucose, 2 -h plasma glucose and self-reported diagnoses of T2DM were used in the analysis. Multinomial logistic regression was used to examine the determinants of prediabetes and T2DM. The average predicted probabilities of T2DM developing or presenting were determined for the different ages and levels of BMI in each population.

Results: Chinese participants had a higher adjusted prevalence of T2DM (men $12.8 \%$ vs. 4.6\%; women $10.6 \%$ vs. $3.1 \%$ ) and prediabetes (men $12.4 \%$ vs. $12.2 \%$; women $14.4 \%$ vs. $12.2 \%)$ than Swedish participants. Age, overweightedness/obesity, hypertension and a family history of diabetes were significant risk factors for prediabetes and T2DM. In both populations, the predicted probability of T2DM increased as the BMI increased in all age groups.
A. Santosa $\cdot$ N. Ng
Department of Public Health and Community
Medicine, Institution of Medicine, Sahlgrenska
Academy, University of Gothenburg, Gothenburg, Sweden
Y. Jiang
Songjiang District Centre for Disease Prevention and Control, Shanghai, China 
At the same BMI level, Chinese participants were more likely to have T2DM compared to their Swedish counterparts. The average predicted probability of T2DM was less than $20 \%$ in nearly all age groups among Swedish women.

Conclusions: Chinese adults had the higher prevalence of prediabetes and T2DM and a higher probability of T2DM at the same BMI level compared with Swedish adults. These results indicate the importance of addressing the ongoing obesity epidemic as a matter of urgency in order to curb what has become an apparent diabetes epidemic in both countries.

Keywords: Body mass index; Prediabetes; Prevalence; Risk factors; Type 2 diabetes

\section{INTRODUCTION}

Diabetes mellitus (DM) is a group of metabolic disorders characterised by elevated blood glucose concentration and increased insulin resistance. Type $2 \mathrm{DM}(\mathrm{T} 2 \mathrm{DM})$ is a major cause of morbidity, mortality and high healthcare costs worldwide [1]. The global prevalence of T2DM among adults has increased during recent decades, especially in low- and middle-income countries (LMICs) [2, 3]. The International Diabetes Federation (IDF) estimates that in 2017, 425 million individuals worldwide ( $8.8 \%$ of the world population) were living with T2DM. The IDF also predicted that in 2045 the number of adults (those aged 20-79 years old) with T2DM will have increased to 629 million and that there will be four million deaths attributable to T2DM: equivalent to $10.7 \%$ of all-cause mortality [4]. The prevalence of T2DM varies among countries and regions. About 79\% of patients with T2DM live in LMICs, where the largest increase in the burden of T2DM is forecasted to occur [5]. In 2017, the age-adjusted prevalence of T2DM was higher in Southeast Asia than in Europe (10.1\% vs. 6.8\%) [6]. Both Sweden and China have experienced an epidemiological transition from a predominance of infectious diseases to non-communicable diseases (NCDs). This transition occurred more rapidly in China than in Sweden [7]. China has the largest number of adults with T2DM, with a prevalence of $10.9 \%$ in 2013 based on a national representative survey
$[8,9]$. Sweden has a T2DM prevalence of $7.0 \%$, but this is projected to increase to $10.4 \%$ by the year 2050 [10]. During the transition stage, when blood glucose levels are higher than normal but lower than the threshold used for the diagnosis of T2DM, prediabetes is considered a significant risk factor for T2DM and macrovascular diseases [11]. Accordingly, it is the characterisation and identification of individuals in the prediabetic state that is important for the prevention, management and treatment of T2DM $[4,12]$.

Most studies of TD2M have been conducted in countries with comparable socioeconomic structures. However, between China and Sweden there is a difference in the prevalence of adult T2DM: the Chinese population appears more disposed towards developing T2DM because of the nation's dramatic urbanization, that is ongoing, and its unique approach to nutrition. Despite this evidence, there have to date been no large, representative, populationbased comparative epidemiological studies which measure the burden of prediabetes and T2DM in China and Sweden. In addition, it is unclear whether the risks of prediabetes and T2DM differ between the two countries. A comparison of two populations living in different socioeconomic and political environments could help identify the burdens, as well as the behavioural and environmental factors, associated with prediabetes and T2DM. Accurate estimation of prediabetes and T2DM is necessary for raising public awareness, developing public health strategies, and allocating health resources for effective prevention and management.

The purpose of this explorative comparative study was to determine the prevalence of prediabetes and T2DM and the associated risk factors in eastern China and northern Sweden. Furthermore, the present study aimed to explore the effect of high BMI on the probability of T2DM being present among adults in both countries.

\section{METHODS}

\section{Study Populations}

This study used data collected from two population-based cross-sectional surveys: the 
Shanghai Survey of Eastern China, collected during June 2016 and December 2017; and the Västerbotten Intervention Program (VIP) (Västerbotten County, northern Sweden), collected from 2014 to 2017.

The Shanghai Survey is a part of national population cohort study conducted in eastern China that aimed to establish a large-scale regional cohort database for NCDs. We adopted a multistage stratified clustered sampling method to recruit participants. At stage one, four communities (Zhongshan, Xinqiao, Sheshan and Maogang) were selected on the basis of geographic region, economic status and willingness to participate. At stage two, onethird of the committees/villages were randomly selected from each community. At stage three, we selected adults aged 35-64 years who had lived in Shanghai for more than 5 years, with a final sample of 25,356 participants. After exclusion of individuals who lacked data in any of the variables $(5.1 \%, n=1301), 24,055$ individuals were used in the final analysis.

The VIP is a long-term cardiovascular disease (CVD) prevention programme conducted in northern Sweden with the aim of reducing mortality from CVD and diabetes. The VIP is integrated into ordinary primary care routines. All residents who turn 40, 50 or 60 years old in Västerbotten County are invited for a health examination at their primary health centre. During 2014-2017, 25,511 participants were enrolled. After the exclusion of individuals who lacked data in any of the variables $(8.4 \%$, $n=2134), 23,377$ individuals were used in the final analyses. Using the state-issued 'unique person numbers', Statistics Sweden linked the VIP data with the population register data on socioeconomic indicators. The anonymous linked dataset is hosted by the Department of Epidemiology and Global Health, Umeå University in the Edwin database.

\section{Ethical Approval}

The Shanghai Survey protocol was approved by the ethical review committee of the School of Public Health, Fudan University (IRB approval number 2016-04-0586). In Sweden, the use of the Edwin database for this research has been approved by the Regional Ethical Committee at Umeå University (EPN 14-06-05 (Dnr 2014 196-32 M)). Written informed consent was obtained from all study participants prior to the study.

\section{Data Collection}

\section{Questionnaires}

The Shanghai Survey used an electronic standardized questionnaire that contained questions on demographics (sex, age, marital status, education level), health-related behaviours (smoking, drinking, physical activity), and family history of chronic diseases. Individuals were categorised by age as 35-44, $45-54$ or 55-64 years old. Smoking status was "never smoked", "ex-smoker" or "current smoker" based on responses to the questions "Have you ever smoked at least one cigarette every day for more than 6 months?" and "What is your current smoking status?" Alcohol consumption was determined on the basis of the response to the question "Have you consumed alcohol at least three times a week for more than 6 months?" Physical activity was classified as "high", "moderate" or "low" on the basis of responses to the International Physical Activity Questionnaire Short Form [13].

The VIP study used a standardized questionnaire that collected information on lifestyle behaviours such as smoking, drinking and physical activity, history of chronic diseases and use of medicines, and sociodemographic factors. The VIP participants were categorised by age as 40,50 or 60 years old. Smoking status was "never smoked", "ex-smoker" or "current smoker" based on responses to the question "Do you currently smoke?" We defined ex-smokers as those who had previously smoked daily/occasionally and current smokers as those who currently smoked intermittently or daily. Alcohol consumption levels were ascertained on the basis of participants' responses to the question "How often do you drink alcohol?" and divided between "no" (for 'never' and 'once a month or less') and "yes" (at least twice a month). Physical activity was classified as "high", "moderate" or 
"low" on the basis of responses to questions regarding the work commute, recreational time and physical exercise, as previously described [14].

Both surveys classified marital status as "currently married" (married and cohabiting) or "currently unmarried" (unmarried, widowed or divorced). Education level was categorised as "low" (completion of 9 years of compulsory education), "medium" (completion of 12 years of education) or "high" (graduation from a university). A family history of chronic diseases was determined by asking whether any family member suffered from conditions such as cardiovascular diseases, diabetes mellitus or hypertension.

\section{Anthropometric Measurements}

Height and weight were measured while participants were barefoot and wearing light clothing. Height was accurate to $0.1 \mathrm{~cm}$ and weight was accurate to $0.1 \mathrm{~kg}$. BMI $\left(\mathrm{kg} / \mathrm{m}^{2}\right)$ was then calculated. The Shanghai Survey used the criteria proposed by the Working Group on Obesity in China (WGOC) [15] to define "overweight" as a BMI of $24-27.9 \mathrm{~kg} / \mathrm{m}^{2}$ and "obese" as a BMI of $28 \mathrm{~kg} / \mathrm{m}^{2}$ or more. The VIP survey used the World Health Organization (WHO) recommendations for categorising BMI as "overweight" $\left(25.0-29.9 \mathrm{~kg} / \mathrm{m}^{2}\right)$ and "obese" (30 kg/m² or more) [16].

\section{Blood Pressure Measurement}

The Shanghai Survey measured blood pressures using a digital sphygmomanometer on the right arm while the participant was seated having rested for $5 \mathrm{~min}$. Three measurements were taken and the mean values were recorded. Hypertension was defined as a resting systolic blood pressure (SBP) of $140 \mathrm{mmHg}$ or more and/ or a diastolic blood pressure (DBP) of $90 \mathrm{mmHg}$ or more.

The VIP measured blood pressure using a manual sphygmomanometer on the right midarm at the level of the heart while the participant was seated. Respondents were asked to rest for at least $5 \mathrm{~min}$ before two measurements were taken, and the average of those two measurements was recorded. The participants were also asked if they had used any blood pressure-lowering medications in the 14 days prior to being measured. Hypertension was defined as a resting SBP of $140 \mathrm{mmHg}$ or more and/or a DBP of $90 \mathrm{mmHg}$ or more, and/or the use of medications for hypertension during the preceding 14 days.

\section{Blood Sampling and Measurements}

Blood samples were collected in the morning after an overnight fast. The Shanghai Survey stored samples at $-80^{\circ} \mathrm{C}$ for no more than $6 \mathrm{~h}$ prior to them being transported to the Shanghai Dian Diagnostics Co. Ltd. for analysis. Glycated haemoglobin (HbA1c) was measured using high pressure liquid chromatography (TOSOH G8, automatic haemoglobin A1c analyser). The VIP survey determined fasting blood glucose (FPG) and 2-h plasma glucose (2hPG) measured in a $75-g$ oral glucose tolerance test from capillary plasma samples using a Reflotron benchtop analyser (Boehringer Mannheim GmbH, Mannheim, Germany).

The Shanghai Survey determined serum total cholesterol (TC) using enzyme colorimetry (Roche COBAS C501 automatic biochemical analyser) and defined hypercholesterolaemia as total serum cholesterol of $6.2 \mathrm{mmol} / \mathrm{L}$ or more [17]. The VIP used a Reflotron benchtop analyser (Roche Diagnostics) and defined hypercholesterolaemia using the same threshold (serum cholesterol of $6.2 \mathrm{mmol} / \mathrm{L}$ or more) and/ or the use of a lipid-lowering medication during the preceding 14 days.

\section{Main Outcome}

The main outcome measurement was the presence of prediabetes or T2DM. T2DM was defined on the basis of a combination of a selfreported questionnaire ("Have you been diagnosed by a healthcare professional as having T2DM?") and blood measurement (HbA1c as a diagnostic tool in the Shanghai Survey; FPG and $2 \mathrm{hPG}$ as the diagnostic tools in the VIP). Participants with T2DM were then classified as having a diagnosis of T2DM from a doctor or as having undiagnosed T2DM if they had no diagnosis from a doctor but an abnormal blood 
test. The Shanghai Study used an HbA1c cut-off value from the American Diabetes Association (ADA) [18] and the WHO criteria [19]. The VIP only used the WHO criteria, because only capillary blood samples were available. Prediabetes was defined as the absence of T2DM, but the presence of an abnormal blood measurement based on the ADA and WHO criteria. Table S1 in the supplementary material summarises the diagnostic criteria used in the Shanghai and VIP surveys.

\section{Statistical Analysis}

The descriptive statistics of categorical variables were presented as frequency and percentage. To enable a comparison between the two populations, we calculated the age- and education-adjusted prevalence of prediabetes and T2DM. Multinomial logistic regression models with enter selection method were used to examine any association between sociodemographic, lifestyle and biological factors and the prevalence of prediabetes or T2DM, by sex, for the Chinese and Swedish populations. The dependent variable was categorised into three groups of 'normal blood glucose' (as per the reference category), 'prediabetes' and 'T2DM'. The associations between the independent variables and prediabetes and T2DM were presented using adjusted odds ratios (OR) and 95\% confidence intervals (CI). Following the logistic regression analysis, we conducted post-estimation analyses to estimate the predicted probabilities of T2DM in different age groups for individuals with different levels of BMIs (as a continuous scale). All the analyses were stratified by sex. Data analyses were performed using Stata Version 15.1 (StataCorp, College Station, Texas, USA). Statistical significance was set at $p<0.05$ for the two-sided test.

\section{RESULTS}

Table 1 shows the general characteristics of the study populations in China and Sweden. Most participants in the Shanghai Survey had low levels of education $(77.8 \%$ of men and $85.1 \%$ of women). By contrast, less than $10 \%$ of VIP respondents had low levels of education $(7.7 \%$ of men and $6.2 \%$ of women). There were more male 'current smokers' in the Shanghai Survey $(53.6 \%)$ than in the VIP survey $(11.3 \%)$. Chinese women were less likely to smoke or to drink alcohol than Swedish women (smoking $0.2 \%$ vs. $10.6 \%$; drinking $0.8 \%$ vs. $14.6 \%$, respectively). The prevalence of hypercholesterolaemia was higher among VIP participants than among Shanghai participants.

Figure 1 shows the prevalence of prediabetes and T2DM (using the WHO criteria) after adjusting for age and education level in China and Sweden. Overall, the adjusted prevalence of prediabetes and T2DM are higher among the older age groups. The prevalence of T2DM is higher in the Shanghai Survey than in the VIP (men $12.8 \%$, 95\% CI $12.1-13.4 \%$ vs. $4.6 \%, 95 \%$ CI 4.3-5.1\%; women $10.6 \%$, 95\% CI $10.1-11.1 \%$ vs. $3.1 \%$, 95\% CI $2.8-3.4 \%)$. The estimated prevalence of prediabetes was slightly higher among Shanghai participants than VIP participants (men $12.4 \%$ vs. $12.2 \%$; women $14.4 \%$ vs. $12.2 \%$ ). The adjusted prevalence of prediabetes based on the ADA criteria in China was $32.5 \%$ (95\% CI $31.5-33.4 \%)$ in men and $36.4 \%$ (95\% CI $35.6-37.2 \%$ ) in women (Fig. S1 in the supplementary material).

Table 2 presents the findings of factors associated with prediabetes and T2DM among men in both countries. For Chinese men, the adjusted model indicated that the odds of prediabetes and T2DM were greater among those who were older, overweight or obese, had hypercholesterolaemia, hypertension and a family history of T2DM. Alcohol consumption was a protective factor $(\mathrm{aOR}=0.85, \quad 95 \% \quad \mathrm{CI}$ 0.74-0.98) for prediabetes. Analysis of Swedish men indicated that men who were older, unmarried, had sedentary physical activity, were overweight or obese, had hypertension and a family history of T2DM were significantly more likely to have prediabetes and T2DM. Also, men who received anti-lipid treatment and had a controlled cholesterol level showed greater odds of having prediabetes $(\mathrm{aOR}=1.64$, $95 \%$ CI $1.35-1.98)$ and $\mathrm{T} 2 \mathrm{DM}(\mathrm{aOR}=4.15,95 \%$ CI 3.33-5.16). By contrast, Swedish men with untreated hypercholesterolaemia had lower odds of having prediabetes $(\mathrm{aOR}=0.65,95 \% \mathrm{CI}$ 
Table 1 Characteristics of the study participants from eastern China and northern Sweden

\begin{tabular}{|c|c|c|c|c|}
\hline \multirow[t]{2}{*}{ Variables } & \multicolumn{2}{|c|}{ Eastern China $(N=24,055)$} & \multicolumn{2}{|c|}{ Northern Sweden $(N=23,377)$} \\
\hline & $\overline{\operatorname{Men}(n, \%)}$ & Women $(n, \%)$ & $\operatorname{Men}(n, \%)$ & Women $(n, \%)$ \\
\hline \multicolumn{5}{|l|}{ Sociodemographic factors } \\
\hline \multicolumn{5}{|l|}{ Age } \\
\hline $35-44$ in China/40 years in Sweden & $1141(12.3)$ & $1901(12.8)$ & $3717(32.0)$ & $3653(31.0)$ \\
\hline $45-54$ in China/50 years in Sweden & $3304(35.7)$ & $5946(40.2)$ & $4029(34.7)$ & $4078(34.6)$ \\
\hline $55-64$ in China/60 years in Sweden & $4805(52.0)$ & $6958(47.0)$ & $3856(33.2)$ & $4044(34.3)$ \\
\hline \multicolumn{5}{|l|}{ Marital status } \\
\hline Currently married & $8971(97.0)$ & $14,042(94.8)$ & $9066(78.1)$ & $9445(80.2)$ \\
\hline Currently unmarried & $279(3.0)$ & $763(5.2)$ & $2536(21.9)$ & $2330(19.8)$ \\
\hline \multicolumn{5}{|l|}{ Education level } \\
\hline High (13 or more years) & $409(4.4)$ & $520(3.5)$ & $3797(32.7)$ & $5694(48.4)$ \\
\hline Medium (10-12 years) & $1642(17.8)$ & $1683(11.4)$ & $6908(59.5)$ & $5356(45.5)$ \\
\hline Low (up to 9 years) & $7199(77.8)$ & $12,602(85.1)$ & $897(7.7)$ & $725(6.2)$ \\
\hline \multicolumn{5}{|l|}{ Risk behaviours } \\
\hline \multicolumn{5}{|l|}{ Smoking } \\
\hline Never smoked & $3617(39.1)$ & $14,761(99.7)$ & $7358(63.4)$ & $6810(57.8)$ \\
\hline Ex-smokers & $679(7.3)$ & $8(0.1)$ & $2928(25.2)$ & $3722(31.6)$ \\
\hline Current smokers & $4954(53.6)$ & $36(0.2)$ & $1316(11.3)$ & $1243(10.6)$ \\
\hline \multicolumn{5}{|l|}{ Alcohol consumption } \\
\hline No & $6238(67.4)$ & $14,688(99.2)$ & $9514(82.0)$ & $10,051(85.4)$ \\
\hline Yes & $3012(32.6)$ & $117(0.8)$ & $2088(18.0)$ & $1724(14.6)$ \\
\hline \multicolumn{5}{|l|}{ Physical activity level } \\
\hline Low & $6615(71.5)$ & $9683(65.4)$ & $2167(18.7)$ & $1186(10.1)$ \\
\hline Moderate & $1958(21.2)$ & $4087(27.6)$ & $5512(47.5)$ & $5976(50.8)$ \\
\hline High & $677(7.3)$ & $1035(7.0)$ & $3923(33.8)$ & $4613(39.2)$ \\
\hline \multicolumn{5}{|l|}{ Biological factors } \\
\hline \multicolumn{5}{|l|}{ Body mass index } \\
\hline Underweight/normal & 3693 (39.9) & $7724(52.2)$ & $3475(30.0)$ & $5421(46.0)$ \\
\hline Overweight & $4165(45.0)$ & $5382(36.4)$ & $5423(46.7)$ & $3860(32.8)$ \\
\hline Obese & $1392(15.0)$ & $1699(11.5)$ & $2704(23.3)$ & $2494(21.2)$ \\
\hline Hypertension & $3613(39.1)$ & $5363(36.2)$ & $5109(44.0)$ & $3587(30.5)$ \\
\hline Hypercholesterolaemia & $617(6.7)$ & $1487(10.0)$ & $2650(22.8)$ & $2538(21.6)$ \\
\hline Family history of T2DM & $1115(12.1)$ & $2056(13.9)$ & $2454(21.2)$ & $3016(25.6)$ \\
\hline
\end{tabular}


Table 1 continued

\begin{tabular}{|c|c|c|c|c|}
\hline \multirow[t]{2}{*}{ Variables } & \multicolumn{2}{|c|}{ Eastern China $(N=24,055)$} & \multicolumn{2}{|c|}{ Northern Sweden $(N=23,377)$} \\
\hline & $\operatorname{Men}(n, \%)$ & Women $(n, \%)$ & $\operatorname{Men}(n, \%)$ & Women $(n, \%)$ \\
\hline Family history of CVD/hypertension & $4280(46.3)$ & $7442(50.3)$ & $2119(18.3)$ & $2408(20.5)$ \\
\hline Self-reported diagnosis of diabetes & $767(8.3)$ & $997(6.7)$ & $315(2.7)$ & $202(1.7)$ \\
\hline Self-reported use of diabetes medication & - & - & $284(2.5)$ & $177(1.5)$ \\
\hline
\end{tabular}

CVD cardiovascular diseases, $T 2 D M$ type 2 diabetes mellitus

(A) Men

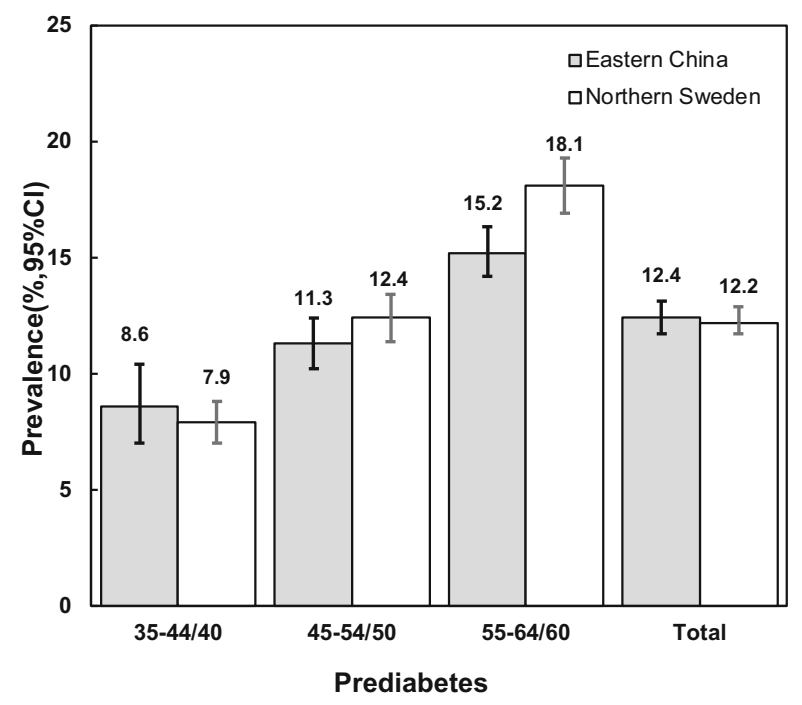

(B) Women

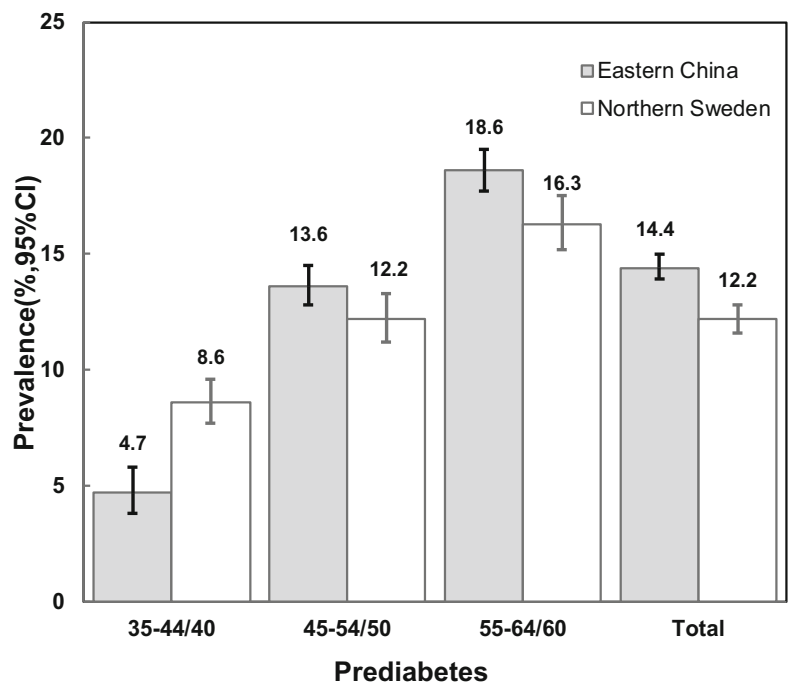

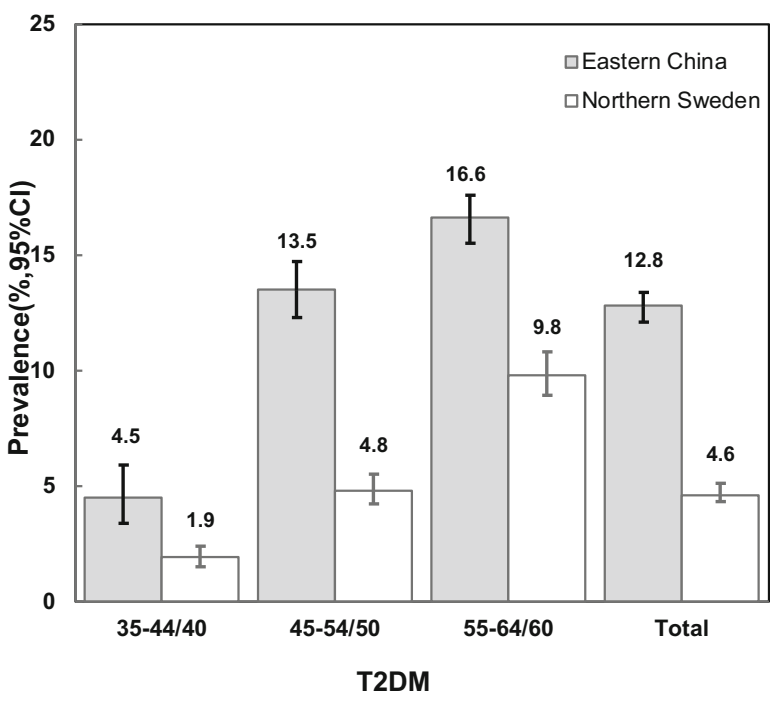

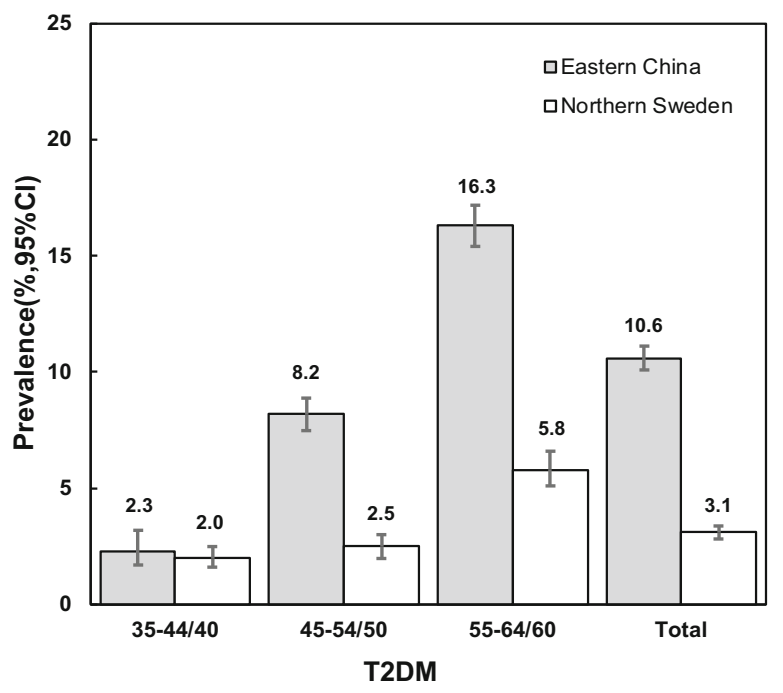

Fig. 1 Prevalence of prediabetes and T2DM (according to WHO criteria) after adjusting for age and education level among men and women in eastern China and northern Sweden. (Error bars indicate 95\% confidence intervals) 
Table 2 Adjusted odds ratio (OR) and 95\% confidence interval (CI) for prediabetes and T2DM compared with normal glucose among men in eastern China and in northern Sweden

\begin{tabular}{|c|c|c|c|c|}
\hline & \multicolumn{2}{|l|}{ Eastern China } & \multicolumn{2}{|l|}{ Northern Sweden } \\
\hline & $\begin{array}{l}\text { Prediabetes } \\
\text { aOR (95\% CI) }\end{array}$ & $\begin{array}{l}\text { T2DM } \\
\text { aOR (95\% CI) }\end{array}$ & $\begin{array}{l}\text { Prediabetes } \\
\text { aOR }(95 \% \text { CI })\end{array}$ & $\begin{array}{l}\text { T2DM } \\
\text { aOR (95\% CI) }\end{array}$ \\
\hline \multicolumn{5}{|l|}{ Sociodemographic factors } \\
\hline \multicolumn{5}{|l|}{ Age } \\
\hline $35-44$ in China/40 years in Sweden & Ref & Ref & Ref & Ref \\
\hline $45-54$ in China/50 years in Sweden & $\begin{array}{l}1.45^{* * *} \\
\quad(1.14-1.87)\end{array}$ & $\begin{array}{l}3.48^{* * *} \\
(2.54-4.75)\end{array}$ & $\begin{array}{l}1.58^{* * *} \\
\quad(1.34-1.84)\end{array}$ & $\begin{array}{l}2.10^{* * *} \\
\quad(1.57-2.80)\end{array}$ \\
\hline $55-64$ in China/60 years in Sweden & $\begin{array}{l}2.35^{* * *} \\
\quad(1.85-2.99)\end{array}$ & $\begin{array}{l}5.35^{* * *} \\
\quad(3.93-7.28)\end{array}$ & $\begin{array}{l}2.32^{* * *} \\
\quad(1.97-2.72)\end{array}$ & $\begin{array}{l}3.65^{* * *} \\
\quad(2.74-4.86)\end{array}$ \\
\hline \multicolumn{5}{|l|}{ Marital status } \\
\hline Currently married & Ref & Ref & Ref & Ref \\
\hline Currently unmarried & $1.08(0.73-1.60)$ & $0.76(0.54-1.08)$ & $\begin{array}{l}1.32^{* * *} \\
\quad(1.16-1.50)\end{array}$ & $\begin{array}{l}1.72^{* * *} \\
\quad(1.42-2.07)\end{array}$ \\
\hline \multicolumn{5}{|l|}{ Education level } \\
\hline High (13 or more years) & Ref & Ref & Ref & Ref \\
\hline Medium (10-12 years) & $1.21(0.82-1.78)$ & $1.19(0.78-1.81)$ & $1.01(0.89-1.16)$ & $1.06(0.85-1.31)$ \\
\hline Low (up to 9 years) & $1.11(0.77-1.61)$ & $1.15(0.77-1.72)$ & $1.09(0.88-1.36)$ & $1.10(0.80-1.51)$ \\
\hline \multicolumn{5}{|l|}{ Risk behaviours } \\
\hline \multicolumn{5}{|l|}{ Smoking } \\
\hline Never smoked & Ref & Ref & Ref & Ref \\
\hline Ex-smokers & $1.30^{*}(1.02-1.66)$ & $1.06(0.83-1.35)$ & $1.16^{*}(1.01-1.32)$ & $1.12(0.92-1.36)$ \\
\hline Current smokers & $1.33^{*}(1.16-1.52)$ & $1.13(0.99-1.30)$ & $\begin{array}{l}1.29^{* * *} \\
\quad(1.08-1.53)\end{array}$ & $1.27(0.98-1.65)$ \\
\hline \multicolumn{5}{|l|}{ Alcohol consumption } \\
\hline No & Ref & Ref & Ref & Ref \\
\hline Yes & $0.85^{*}(0.74-0.98)$ & $0.88(0.77-1.01)$ & $0.99(0.85-1.15)$ & $0.82(0.64-1.05)$ \\
\hline \multicolumn{5}{|l|}{ Physical activity level } \\
\hline High & Ref & Ref & Ref & Ref \\
\hline Moderate & $0.79(0.61-1.03)$ & $0.86(0.67-1.11)$ & $1.10(0.96-1.25)$ & $\begin{array}{l}1.66^{* * *} \\
\quad(1.32-2.09)\end{array}$ \\
\hline Low & $0.86(0.68-1.09)$ & $0.77(0.62-1.01)$ & $1.23^{*}(1.04-1.45)$ & $\begin{array}{l}1.85^{* * *} \\
\quad(1.42-2.41)\end{array}$ \\
\hline
\end{tabular}


Table 2 continued

\begin{tabular}{|c|c|c|c|}
\hline \multicolumn{2}{|l|}{ Eastern China } & \multicolumn{2}{|c|}{ Northern Sweden } \\
\hline $\begin{array}{l}\text { Prediabetes } \\
\text { aOR }(95 \% \mathrm{CI})\end{array}$ & $\begin{array}{l}\text { T2DM } \\
\text { aOR }(95 \% \mathrm{CI})\end{array}$ & $\begin{array}{l}\text { Prediabetes } \\
\text { aOR }(95 \% \mathrm{CI})\end{array}$ & $\begin{array}{l}\text { T2DM } \\
\text { aOR }(95 \% \mathrm{CI})\end{array}$ \\
\hline
\end{tabular}

\section{Biological factors}

Body mass index

Underweight/normal

\begin{tabular}{lll} 
Ref & \multicolumn{1}{l}{ Ref } & \multicolumn{1}{l}{ Ref } \\
$1.61^{* * *}$ & $1.73^{* * *}$ & $1.44^{* * *}$ \\
$(1.40-1.86)$ & $(1.50-2.00)$ & $(1.24-1.68)$
\end{tabular}

Obese

$$
\begin{array}{lr}
2.29^{* * *} & 2.88^{* * *} \\
(1.90-2.75) & (2.40-3.45)
\end{array}
$$

$2.39^{* * *}$

(2.02-2.83)

Ref

Overweight

$$
\text { Ref }
$$

Ref

Ref

Ref

\section{Normal}

Hypercholesterolaemia

$1.71^{* * *}$

$$
\text { (1.37-2.13) }
$$

$1.76^{* * *}$$$
(1.41-2.19)
$$

Normal cholesterol-treated

$$
-
$$

Hypercholesterolaemia-untreated

Hypercholesterolaemia-treated

Hypertension

$$
\text { No }
$$

Yes

$$
\begin{aligned}
& \text { Ref } \\
& 1.16^{*}(1.02-1.31)
\end{aligned}
$$$$
-
$$

$1.64^{* * *}$

(1.35-1.98)

$0.65^{* * *}$

(0.56-0.75)

$0.86(0.39-1.88)$

Ref

$1.60^{* * *}$

$(1.41-1.81)$

$$
\text { (1.05-1.35) }
$$
Ref
$3.77^{* * *}$
$(3.21-4.44)$

$$
\begin{aligned}
& \text { Ref } \\
& \begin{array}{l}
1.51^{* * *} \\
(1.24-1.84)
\end{array}
\end{aligned}
$$

Family history of CVD/hypertension

No

Ref

Ref

Ref

$1.22^{* * *}$

(1.07-1.40)

$4.15^{* * *}$

$0.47^{* * *}$

$$
\text { (0.36-0.61) }
$$

$2.49^{*}(1.17-5.29)$

Yes

$1.02(0.90-1.17)$

$0.92(0.81-1.05)$
Ref

Ref

$0.92(0.80-1.07)$
Ref

$2.02^{* * *}$

(1.64-2.49)

Ref

$2.49^{* * *}$

(2.08-2.97)

WHO criteria were used to define T2DM and prediabetes ${ }^{*} p<0.05,{ }^{* * *} p<0.001$ 
Table 3 Adjusted odds ratio (OR) and 95\% confidence interval (CI) for prediabetes and T2DM compared with normal glucose among women in eastern China and in northern Sweden

\begin{tabular}{|c|c|c|c|c|}
\hline & \multicolumn{2}{|l|}{ Eastern China } & \multicolumn{2}{|l|}{ Northern Sweden } \\
\hline & $\begin{array}{l}\text { Prediabetes } \\
\text { aOR }(95 \% \text { CI })\end{array}$ & $\begin{array}{l}\text { T2DM } \\
\text { aOR }(95 \% \mathrm{CI})\end{array}$ & $\begin{array}{l}\text { Prediabetes } \\
\text { aOR (95\% CI) }\end{array}$ & $\begin{array}{l}\text { T2DM } \\
\text { aOR }(95 \% \mathrm{CI})\end{array}$ \\
\hline \multicolumn{5}{|l|}{ Sociodemographic factors } \\
\hline \multicolumn{5}{|l|}{ Age } \\
\hline $\begin{array}{l}35-44 \text { in China/ } 40 \text { years in } \\
\text { Sweden }\end{array}$ & Ref & Ref & Ref & Ref \\
\hline $\begin{array}{l}45-54 \text { in China/ } 50 \text { years in } \\
\text { Sweden }\end{array}$ & $\begin{array}{l}3.03^{* * *} \\
\quad(2.39-3.86)\end{array}$ & $3.26^{* * *}(2.32-4.59)$ & $\begin{array}{l}1.34^{* * *} \\
\quad(1.15-1.57)\end{array}$ & $0.89(0.64-1.23)$ \\
\hline $\begin{array}{l}55-64 \text { in China/ } 60 \text { years in } \\
\text { Sweden }\end{array}$ & $\begin{array}{l}4.80^{* * *} \\
\quad(3.78-6.09)\end{array}$ & $\begin{array}{l}7.58^{* * *} \\
\quad(5.04-10.04)\end{array}$ & $\begin{array}{l}1.92^{* * *} \\
\quad(1.63-2.27)\end{array}$ & $\begin{array}{l}1.60^{* * *} \\
\quad(1.16-2.20)\end{array}$ \\
\hline \multicolumn{5}{|l|}{ Marital status } \\
\hline Currently married & Ref & Ref & Ref & Ref \\
\hline Currently unmarried & $1.05(0.85-1.30)$ & $0.97(0.77-1.23)$ & $1.01(0.88-1.16)$ & $1.05(0.82-1.34)$ \\
\hline \multicolumn{5}{|l|}{ Education level } \\
\hline High (13 or more years) & Ref & Ref & Ref & Ref \\
\hline Medium (10-12 years) & $1.00(0.68-1.48)$ & $1.68(0.85-3.32)$ & $0.99(0.87-1.11)$ & $1.19(0.95-1.50)$ \\
\hline Low (up to 9 years) & $0.98(0.68-1.43)$ & $2.11(1.09-4.10)$ & $\begin{array}{l}1.35^{* * *} \\
\quad(1.08-1.68)\end{array}$ & $1.62^{*}(1.12-2.34)$ \\
\hline
\end{tabular}

Risk behaviours

Smoking ${ }^{a}$

Never smoked

Ex-smokers

Current smokers

Alcohol consumption ${ }^{a}$

No

Yes

Physical activity level

High

Moderate

Low

Biological factors

Obesity

Normal/underweight

$$
\begin{array}{ll}
\text { Ref } & \text { Ref } \\
1.01(0.83-1.22) & 0.93(0.75-1.14) \\
0.94(0.78-1.13) & 0.71(0.58-0.87)
\end{array}
$$

Ref

Ref

$0.96(0.85-1.09)$

$0.94(0.75-1.19)$

$1.12(0.93-1.35)$

$1.55^{* * *}$

$$
(1.14-2.10)
$$

Ref

Ref

$1.01(0.86-1.19)$

$0.96(0.69-1.34)$
Ref
Ref
Ref
Ref 
Table 3 continued

\begin{tabular}{|c|c|c|c|c|}
\hline & \multicolumn{2}{|l|}{ Eastern China } & \multicolumn{2}{|l|}{ Northern Sweden } \\
\hline & $\begin{array}{l}\text { Prediabetes } \\
\text { aOR (95\% CI) }\end{array}$ & $\begin{array}{l}\text { T2DM } \\
\operatorname{aOR}(95 \% \mathrm{CI})\end{array}$ & $\begin{array}{l}\text { Prediabetes } \\
\text { aOR }(95 \% \text { CI })\end{array}$ & $\begin{array}{l}\text { T2DM } \\
\operatorname{aOR}(95 \% \mathrm{CI})\end{array}$ \\
\hline Overweight & $\begin{array}{l}1.47^{* * *} \\
\quad(1.33-1.63)\end{array}$ & $1.80^{* * *}(1.59-2.04)$ & $\begin{array}{l}1.37^{* * *} \\
\quad(1.20-1.58)\end{array}$ & $\begin{array}{l}1.63^{* * *} \\
\quad(1.22-2.17)\end{array}$ \\
\hline Obese & $\begin{array}{l}1.96^{* * *} \\
\quad(1.69-2.27)\end{array}$ & $3.85^{* * *}(3.30-4.49)$ & $\begin{array}{l}2.42^{* * *} \\
\quad(2.09-2.80)\end{array}$ & $\begin{array}{l}3.75^{* * *} \\
\quad(2.84-4.97)\end{array}$ \\
\hline \multicolumn{5}{|l|}{ Cholesterol level } \\
\hline Normal & Ref & Ref & Ref & Ref \\
\hline Hypercholesterolaemia & $\begin{array}{l}1.37^{* * *} \\
\quad(1.19-1.58)\end{array}$ & $1.37^{* * *}(1.17-1.61)$ & - & - \\
\hline Normal cholesterol-treated & - & - & $\begin{array}{l}1.55^{* * *} \\
\quad(1.22-1.98)\end{array}$ & $\begin{array}{l}6.42^{* * *} \\
\quad(4.82-8.56)\end{array}$ \\
\hline Hypercholesterolaemia-untreated & - & - & $\begin{array}{l}0.63^{* * *} \\
\quad(0.54-0.73)\end{array}$ & $\begin{array}{l}0.62^{* * *} \\
\quad(0.46-0.83)\end{array}$ \\
\hline Hypercholesterolaemia-treated & - & - & $0.80(0.37-1.73)$ & $\begin{array}{l}3.19^{* * *} \\
\quad(1.42-7.19)\end{array}$ \\
\hline \multicolumn{5}{|l|}{ Hypertension } \\
\hline No & Ref & Ref & Ref & Ref \\
\hline Yes & $\begin{array}{l}1.22^{* * *} \\
\quad(1.11-1.35)\end{array}$ & $1.61^{* * *}(1.44-1.79)$ & $\begin{array}{l}1.47^{* * *} \\
\quad(1.29-1.66)\end{array}$ & $\begin{array}{l}2.21^{* * *} \\
\quad(1.75-2.80)\end{array}$ \\
\hline \multicolumn{5}{|l|}{ Family history of T2DM } \\
\hline No & Ref & Ref & Ref & Ref \\
\hline Yes & $\begin{array}{l}1.60^{* * *} \\
\quad(1.39-1.83)\end{array}$ & $3.91^{* * *}(3.42-4.48)$ & $\begin{array}{l}1.35^{* * *} \\
\quad(1.20-1.53)\end{array}$ & $\begin{array}{l}2.25^{* * *} \\
\quad(1.82-2.77)\end{array}$ \\
\hline \multicolumn{5}{|l|}{ Family history of CVD/hypertension } \\
\hline No & Ref & Ref & Ref & Ref \\
\hline Yes & $0.96(0.87-1.06)$ & $0.89(0.79-1.00)$ & $1.03(0.90-1.18)$ & $0.88(0.69-1.12)$ \\
\hline
\end{tabular}

WHO criteria were used to define T2DM and prediabetes ${ }^{*} p<0.05,{ }^{* * *} p<0.001$

a There was no adjustment for smoking and alcohol consumption in Chinese women 


\section{Predicted probability of diabetes}
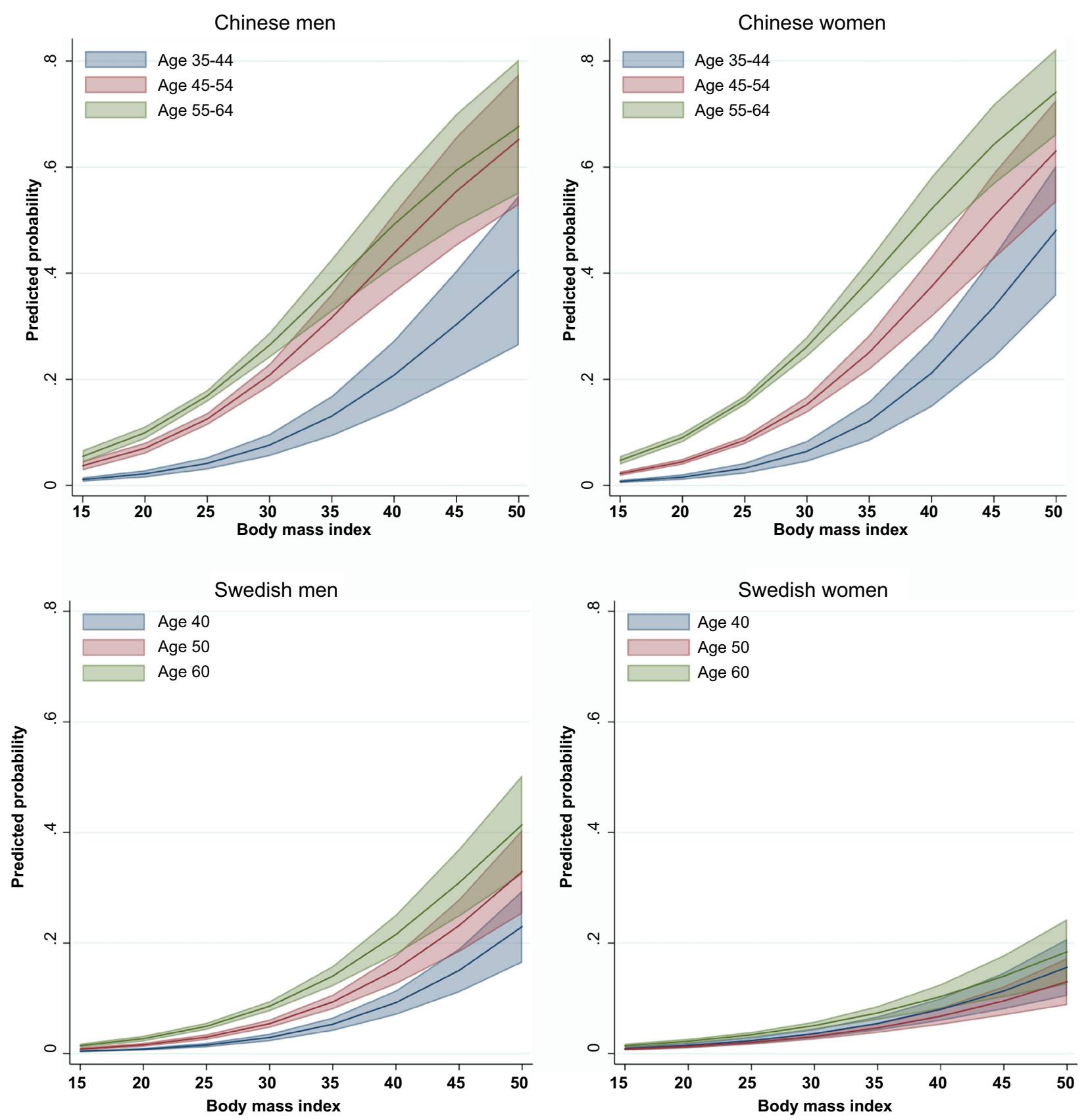

Fig. 2 Predicted probability of T2DM based on BMI among men and women of different age groups in eastern China and northern Sweden

$0.56-0.75)$ and $\mathrm{T} 2 \mathrm{DM} \quad(\mathrm{aOR}=0.47,95 \%$ CI $0.36-0.61)$.

Table 3 shows the factors associated with prediabetes and T2DM among women in China and Sweden. For Chinese women, the odds of prediabetes and T2DM were greater among those who were older, overweight or obese, had a high cholesterol level, hypertension and a family history of T2DM. For Swedish women, those who were older, with a low level of 
education, low physical activity, obesity, hypertension and a family history of T2DM had increased odds of having prediabetes and T2DM. The odds of having prediabetes increased among women who had normal levels of cholesterol with treatment $(\mathrm{aOR}=$ 1.55 , 95\% CI 1.22-1.98). Conversely, hypercholesterolaemia without treatment was a protective factor for prediabetes among VIP participants $(\mathrm{aOR}=0.63,95 \%$ CI $0.54-0.73)$. Swedish women with hypercholesterolaemia who received treatment had higher odds of having T2DM $(\mathrm{aOR}=3.19$, 95\% CI 1.42-7.19), but those with untreated hypercholesterolaemia had decreased odds of having T2DM $(\mathrm{aOR}=0.62,95 \%$ CI 0.46-0.83).

Figure 2 shows the average predicted probability of T2DM as a function of BMI in different age groups by sex in China and Sweden. These results show clearly that as BMI increases, the probability of T2DM increases in both countries. Chinese participants were more likely to have T2DM than Swedish participants with the same level of BMI. Among Chinese participants, there was a large increase in the predicted probability of T2DM between the ages of 45 and 54 , and an even larger increase between the ages of 55 and 64 . In stark contrast to the results for Chinese women, the average predicted probability of having T2DM was less than $20 \%$ in nearly all the age groups for Swedish women.

\section{DISCUSSION}

We estimated the prevalence and risk factors associated with prediabetes and T2DM in China and Sweden. Prediabetes and T2DM were both more prevalent in the Shanghai Survey than they were in the VIP. This may be attributable to genetic factors, other modifiable risk factors, differences in the socioeconomic status, as well as the use of different diagnostic criteria for diabetes diagnosis [20-24]. The prevalence of T2DM in Chinese participants is higher than that reported in a nationally representative survey of Chinese adults in 2013 [8]; however, the prevalence of T2DM in Swedish participants is lower than was estimated by the IDF [6]. Differences in the prevalence of undiagnosed
T2DM reported in studies could be due to the different measurements to diagnose diabetes as measurements of glucose and HbA1c reflect different aspects of glucose metabolism [25, 26]. Considering the inconvenience of performing oral glucose tolerance tests and day-to-day variability in glucose level, HbA1c has been recommended as a tool to diagnose diabetes by International Expert Committee and ADA. In the Shanghai Survey, we used the HbA1c for diagnosis of T2DM (WHO criteria) and found that the adjusted prevalence of prediabetes was about $12 \%$, although the prevalence was about three times higher when using ADA criteria. A recent study from China using ADA criteria showed that almost $50.1 \%$ of the population had prediabetes [27]. High levels of HbA1c indicate a high risk of subsequent T2DM but may overestimate the probability of prediabetes.

This study found sex differences in the prevalence of T2DM. In accordance with previous reports, men had a higher prevalence of T2DM than women in both countries $[28,29]$. Generally, large sex-ratio differences across countries are observed. Both biological and psychosocial factors could be responsible for the observed sex differences in the prevalence of T2DM [30]. Age was one of the strongest determinants of T2DM: surveillance data showed that incidence of T2DM increased with age until about 65 years, after which the incidences seemed to level off [31]. Other epidemiological studies reported that overweightedness/obesity is the most important contributor to the increasing prevalence of T2DM and prediabetes [32-34]. We found that the predicted probability of T2DM increased with BMI, and the comparative risk of T2DM was larger among Chinese participants compared to Swedish participants at the same BMI level. One study confirmed ethnic disparities in the risk of developing BMIassociated diabetes: the impact of an increasing BMI on the risk of developing diabetes was greater for Asians compared with other ethnic groups [35]. It is an established view that people with T2DM are more likely to have a family history of T2DM [36]. Family history reflects genetic susceptibility and lifestyle factors, and may serve as a better predictor and screening 
tool for T2DM [37]. Our results also showed that participants with hypertension were more likely to have T2DM, which is consistent with other studies [38]. The effect of hypercholesterolaemia on prediabetes and T2DM was quite different in China and Sweden. Among Chinese participants, we confirmed that hypercholesterolaemia is associated with T2DM, in keeping with previous reports [39, 40]. However, hypercholesterolaemia without treatment was a protective factor among Swedish participants, but the reasons for this are unclear. The mechanisms responsible for this unexpected result warrant future study. Our data showed that a low education level was associated significantly with prediabetes and T2DM among Swedish women: similar findings were reported from another study in Sweden [41]. An assessment of diabetes knowledge shows that men are twice as likely to have better acquaintance with the disease as compared with women, which further confirmed the high risk of T2DM in women with low education [42]. In addition, we found that unmarried Swedish men had higher odds for having prediabetes and T2DM. Marriage may have a positive effect, encouraging an individual to avoid diseases, which may reduce the risk of diabetes. Thus, we suggest targeting these high-risk groups with prevention and management interventions. A recent analysis reported that alcohol consumption was associated with T2DM [43], although we found that alcohol had a protective effect in Chinese men. Further research is needed to understand this phenomenon.

Our study has several strengths. This is the first comparative population study of T2DM that examined large populations in China and Sweden. Moreover, these surveys provided detailed information on many risk factors and examined the role of sex and BMI on the probability of having T2DM. There were some limitations to our study. First, our research had a cross-sectional design, so it is impossible to infer causal relationships of risk factors with T2DM. Second, there are different cultural and political attitudes to participation in surveys between China and Sweden; thus, selection bias might exist in our study. Third, since the two countries measured different biomarkers in the blood sample for the diagnosis of diabetes, we adopted different diagnostic criteria for T2DM, which may have affected the comparability of results from the two countries. Furthermore, the discordance between HbA1c and either glucosebased test and the lower sensitivity of designated HbA1c cut point needed to be considered in interpreting the results of this study. Finally, as a result of the limited availability of data, we could not consider the impact of some important risk factors, such as dietary habit, ethnicity and genetic factors. Further research is required to study the impact of these factors on T2DM.

\section{CONCLUSIONS}

Our findings show that there exists a larger burden of prediabetes and T2DM among adults in eastern China than in northern Sweden. The positive association between BMI and T2DM, with a higher risk of T2DM at a lower level of obesity in China than in Sweden, points out the importance of urgently addressing the ongoing obesity epidemic in China. It is imperative to adopt early detection and management interventions that target the high-risk groups, and to develop effective intervention strategies for the prevention and treatment of T2DM.

\section{ACKNOWLEDGEMENTS}

We thank the participants of the study.

Funding. This project was mainly supported by the Swedish STINT Initiation Grant to Umeå University in Sweden and Fudan University in China (IB2017-7380), which allowed the researchers to travel, meet and work on the paper. In China, the researchers were also supported by the Shanghai Municipal Education Commission-Gaofeng Discipline Development Project for Public Health and Preventive Medicine and the National Key R \& D Program of China (2017 YFC 0907001). In Sweden, the researchers were supported by the Swedish Forte Network Grant-the Network for International Longitudinal Studies on Ageing (2015-01499). 
No additional funding or sponsorship was received for this study or publication of this article. The Rapid Service Fee was funded by the authors.

Authorship. All named authors meet the International Committee of Medical Journal Editors (ICMJE) criteria for authorship for this article, take responsibility for the integrity of the work as a whole, and have given their approval for this version to be published.

Authorship Contributions. Weibing Wang, Nawi Ng, Lars Weinehall and Genming Zhao conceived and designed this study. Yue Zhang and Ailiana Santosa analysed the data. Yue Zhang, Ailiana Santosa and Yonggen Jiang collected the data. Na Wang, Nawi Ng and Qi Zhao provided significant advice and consultation. Yue Zhang, Weibing Wang and Genming Zhao wrote the manuscript. All authors approved the final manuscript.

Disclosures. Yue Zhang, Ailiana Santosa, $\mathrm{Na}$ Wang, Weibing Wang, Nawi Ng, Qi Zhao, Yonggen Jiang, Lars Weinehall, Genming Zhao declare that there are no personal, financial, commercial, or academic conflicts of interest, and they have nothing to disclose. Since the time of the study, Ailiana Santosa and Nawi Ng have moved affiliations to the Department of Public Health and Community Medicine at the University of Gothenburg, Sweden.

Compliance with Ethics Guidelines. All procedures performed in studies involving human participants were in accordance with the ethical standards of the 1964 Helsinki Declaration and its later amendments or comparable ethical standards. Informed consent was obtained from all individual participants included in the study. The Shanghai Survey protocol was approved by the ethical review committee of the School of Public Health, Fudan University (IRB approval number 2016-04-0586). In Sweden, the use of the Edwin database for this research has been approved by the Regional Ethical Committee at Umeå University (EPN 14-06-05 (Dnr 2014 196-32 M)).
Data Availability. The datasets of our study are available from the corresponding author on reasonable request.

Open Access. This article is distributed under the terms of the Creative Commons Attribution-NonCommercial 4.0 International License (http://creativecommons.org/licenses/ by-nc/4.0/), which permits any noncommercial use, distribution, and reproduction in any medium, provided you give appropriate credit to the original author(s) and the source, provide a link to the Creative Commons license, and indicate if changes were made.

\section{REFERENCES}

1. Guariguata L, Whiting DR, Hambleton I, et al. Global estimates of diabetes prevalence for 2013 and projections for 2035. Diabetes Res Clin Pract. 2014;103(2):137-49.

2. Nanditha A, Ma RC, Ramachandran A, et al. Diabetes in Asia and the Pacific: implications for the global epidemic. Diabetes Care. 2016;39(3):472-85.

3. Ogurtsova K, da Rocha Fernandes J, Huang Y, et al. IDF Diabetes Atlas: global estimates for the prevalence of diabetes for 2015 and 2040. Diabetes Res Clin Pract. 2017;128:40-50.

4. Cho N, Shaw J, Karuranga S, et al. IDF Diabetes Atlas: global estimates of diabetes prevalence for 2017 and projections for 2045. Diabetes Res Clin Pract. 2018;138:271-81.

5. Dagenais GR, Gerstein HC, Zhang X, et al. Variations in diabetes prevalence in low-, middle-, and high-income countries: results from the prospective urban and rural epidemiology study. Diabetes Care. 2016:dc152338.

6. International Diabetes Federation. IDF Diabetes Atlas, 8th edn. Brussels: IDF; 2017.

7. Blas E, Kurup AS. Equity, social determinants and public health programmes. Geneva: World Health Organization; 2010.

8. Wang L, Gao P, Zhang M, et al. Prevalence and ethnic pattern of diabetes and prediabetes in China in 2013. JAMA. 2017;317(24):2515-23. 
9. $\mathrm{Hu} \mathrm{C}, \mathrm{Jia}$ W. Diabetes in China: epidemiology and genetic risk factors and their clinical utility in personalized medication. Diabetes. 2018;67(1):3-11.

10. Andersson T, Ahlbom A, Carlsson S. Diabetes prevalence in Sweden at present and projections for year 2050. PLoS One. 2015;10(11):e0143084.

11. Huang Y, Cai X, Mai W, Li M, Hu Y. Association between prediabetes and risk of cardiovascular disease and all cause mortality: systematic review and meta-analysis. BMJ. 2016;355:i5953.

12. Ligthart S, van Herpt TT, Leening MJ, et al. Lifetime risk of developing impaired glucose metabolism and eventual progression from prediabetes to type 2 diabetes: a prospective cohort study. Lancet Diabetes Endocrinol. 2016;4(1):44-51.

13. Lee PH, Macfarlane DJ, Lam T, Stewart SM. Validity of the international physical activity questionnaire short form (IPAQ-SF): a systematic review. Int J Behav Nutr Phys Act. 2011;8(1):115.

14. Ng N, Söderman K, Norberg M, Öhman A. Increasing physical activity, but persisting social gaps among middle-aged people: trends in Northern Sweden from 1990 to 2007. Global Health Action. 2011;4(1):6347.

15. Wang Y, Mi J, Shan X, Wang QJ, Ge K. Is China facing an obesity epidemic and the consequences? The trends in obesity and chronic disease in China. Int J Obes. 2007;31(1):177.

16. World Health Organization. Obesity: preventing and managing the global epidemic. Geneva: World Health Organization; 2000.

17. Joint Committee for Developing Chinese guidelines on Prevention and Treatment of Dyslipidemia in Adults. Guidelines for the prevention and treatment of dyslipidemia in Chinese adults (2016 revision). Chinese Circ J. 2016;31(10):937-53.

18. American Diabetes Association. 2. Classification and Diagnosis of diabetes: standards of medical care in diabetes-2019. Diabetes Care. 2019;42(Supplement 1):S13-S28.

19. World Health Organization. Definition, diagnosis and classification of diabetes mellitus and its complications: report of a WHO consultation: Part 1 . Diagnosis and classification of diabetes mellitus. Geneva: World Health Organization; 1999.

20. Nieto-Martínez R, Mechanick JI, Brajkovich I, et al. Prevalence of diabetes in three regions of Venezuela. The VEMSOLS study results. Primary Care Diabetes. 2018;12(2):126-32.
21. Akter S, Rahman MM, Abe SK, Sultana P. Prevalence of diabetes and prediabetes and their risk factors among Bangladeshi adults: a nationwide survey. Bull World Health Organ. 2014;92:204A-13A.

22. Bailey SL, Ayles H, Beyers N, et al. Diabetes mellitus in Zambia and the Western Cape province of South Africa: prevalence, risk factors, diagnosis and management. Diabetes Res Clin Pract. 2016;118:1-11.

23. Yang C, Ding Z, Zhou H, et al. Prevalence of prediabetes by the fasting plasma glucose and HbA1c screening criteria among the children and adolescents of Shenzhen, China. J Diabetes. 2018.

24. Hu FB. Globalization of diabetes: the role of diet, lifestyle, and genes. Diabetes Care. 2011;34(6):1249-57.

25. Carson AP, Reynolds $\mathrm{K}$, Fonseca VA, Muntner P. Comparison of $\mathrm{A} 1 \mathrm{C}$ and fasting glucose criteria to diagnose diabetes among US adults. Diabetes Care. 2010;33(1):95-7.

26. International Expert Committee. International Expert Committee report on the role of the A1C assay in the diagnosis of diabetes. Diabetes Care. 2009;32(7):1327-34.

27. Xu Y, Wang L, He J, et al. Prevalence and control of diabetes in Chinese adults. JAMA. 2013;310(9):948-59.

28. Pham NM, Eggleston K. Diabetes prevalence and risk factors among Vietnamese adults: findings from community-based screening programs. Diabetes Care. 2015;38(5):e77-8.

29. Yang W, Lu J, Weng J, et al. Prevalence of diabetes among men and women in China. New Engl J Med. 2010;362(12):1090-101.

30. Kautzky-Willer A, Harreiter J, Pacini G. Sex and gender differences in risk, pathophysiology and complications of type 2 diabetes mellitus. Endocr Rev. 2016;37(3):278-316.

31. Kirkman MS, Briscoe VJ, Clark N, et al. Diabetes in older adults. Diabetes Care. 2012;35(12):2650-64.

32. Al-Goblan AS, Al-Alfi MA, Khan MZ. Mechanism linking diabetes mellitus and obesity. Diabetes Metab Syndr Obes Targets Ther. 2014;7:587.

33. Boles A, Kandimalla R, Reddy PH. Dynamics of diabetes and obesity: epidemiological perspective. Biochim Biophys Acta Mol Basis Dis. 2017;1863(5):1026-36.

34. Caspard H, Jabbour S, Hammar N, et al. Recent trends in the prevalence of type 2 diabetes and the association with abdominal obesity lead to growing 
health disparities in the USA: an analysis of the NHANES surveys from 1999 to 2014. Diabetes Obes Metab. 2018;20(3):667-71.

35. Wong RJ, Chou C, Sinha SR, Kamal A, Ahmed A. Ethnic disparities in the association of body mass index with the risk of hypertension and diabetes. J Community Health. 2014;39(3):437-45.

36. Chiwanga FS, Njelekela MA, Diamond MB, et al. Urban and rural prevalence of diabetes and pre-diabetes and risk factors associated with diabetes in Tanzania and Uganda. Global Health Action. 2016;9(1):31440.

37. Katulanda P, Ranasinghe $P$, Jayawardena $R$, Sheriff $\mathrm{R}$, Matthews D. The influence of family history of diabetes on disease prevalence and associated metabolic risk factors among Sri Lankan adults. Diabet Med. 2015;32(3):314-23.

38. Fukuoka Y, Choi J, Bender MS, Gonzalez P, Arai S. Family history and body mass index predict perceived risks of diabetes and heart attack among community-dwelling Caucasian, Filipino, Korean, and Latino Americans-DiLH Survey. Diabetes Res Clin Pract. 2015;109(1):157-63.
39. de Lima CLJ, de Oliveira PS, Ferreira TMC, et al. Risk factors for type II diabetes mellitus: an integrative review. Int Arch Med. 2016;9.

40. Ding D, Chong S, Jalaludin B, Comino E, Bauman AE. Risk factors of incident type 2-diabetes mellitus over a 3-year follow-up: results from a large Australian sample. Diabetes Res Clin Pract. 2015;108(2):306-15.

41. Agardh EE, Sidorchuk A, Hallqvist J, et al. Burden of type 2 diabetes attributed to lower educational levels in Sweden. Popul Health Metrics. 2011;9:60.

42. Aldossari KK, Aldiab A, Al-Zahrani JM, et al. Prevalence of prediabetes, diabetes, and its associated risk factors among males in Saudi Arabia: a populationbased survey. J Diabetes Res. 2018;2018:2194604.

43. Li XH, Yu FF, Zhou YH, He J. Association between alcohol consumption and the risk of incident type 2 diabetes: a systematic review and dose-response meta-analysis. Am J Clin Nutr. 2016;103(3):818-29. 